\title{
Perceived Factors Responsible for Students' Drop Out of School in Zumo Development Area Song Local Government of Adamawa State, Nigeria
}

\author{
Kamkwis M. Zira, Ph.D ${ }^{1}$ \& Adamu Muhammad Zumo \\ ${ }^{I}$ Department of Educational Foundations, Adamawa State University Mubi, Phone No: \\ 08073535025/08141639093,Kamkwis@Yahoo.Com \\ ${ }^{2}$ Federal College of Education, Yola, Phone No: 0808335359, Gmail: mazumo2013@gmail.com
}

\begin{abstract}
\end{abstract}
The main purpose of the study was to examine school related factors responsible for students dropping out from secondary schools in Zumo Development Area of Adamawa State, Nigeria. A descriptive survey research was adopted for the study. A total of twenty students who had dropped out of school in the past five years were in the study area. They were randomly sampled from five communities out of the nine community secondary schools in Zumo Development area. Data was collected through administering a modified four point likert-type questionnaire to the participants. The data obtained was compiled and analysed using simple percentages. The study revealed that poverty and financial constraints were critical in the dropout phenomenon. The study also revealed that school dropout was primarily grounded in school problems such as school distance and inadequate teacher-student relationship, inadequate resources and facilities as well as irrelevant curriculum content that failed to meet the needs and aspirations of the students. The study recommended that schools learning environment should be child friendly. Teachers as well as pupils should team up to work together to encourage and assist children on the verge of dropping out to remain in school.

Key Words: Dropout; Poverty; Perceived Factors; Student; Distant School

DOI: $10.35942 / \mathrm{ijcab} . v 4 \mathrm{i} 1.110$

\section{Cite this Article:}

Zira, K., \& Zumo, A. (2020). Perceived Factors Responsible for Students' Drop Out of School in Zumo Development Area Song Local Government of Adamawa State, Nigeria. International Journal of Current Aspects, 4(1), 22-32. https://doi.org/10.35942/ijcab.v4i1.110

\section{Introduction}

The major concern in basic education is ensuring that students stay in school until they complete their education. Dropping out of school is a serious problem because it denies individual students of their fundamental human right to education. Students who withdraw from school prematurely end up not obtaining any certificate of graduation. The major social costs of dropping out of school include reduced political participation, increased demand for social services, increased crime rates and poor levels of health. Individual costs include lower earnings, unemployment prospects, and greater likelihood of health problems and limiting their chances of economic and social well-being in the future. (Ahmad, Najeemah and Jamalsafri, 2017). Moreover, student dropout is not only a local issue but has also become a severe problem in many places around the world, especially in developing countries. According to Mohammed, Sivapan and Junaenah (2017), student dropout is a serious problem for both students and the society. Understanding the factors of secondary students drop out of school is one of the key issues in addressing the social 
and economic problems that impede the progress of human resources utilization in developing countries. Completing secondary education is important to facilitate basic entry into employment, besides providing adequate foundation for further progress in an individual's career, as well as enabling to interface with technological utilization. (Fun and Wolters, 2014), Thus, secondary education has ramifications toward improving individual socio-cultural behaviour and the socio-economic growth of a country, essential for national development, particularly in developing countries. Dropping out from secondary school is considered a serious educational, social, and cultural problem (Carlson, 2014). This problem has eaten deep into our society that the aims of training or sending children to school nowadays by parents are unfulfilled and unpleasant. It is against this background that the researchers are concerned to find out the possible factors responsible for students dropout from secondary schools in Zumo development area, Adamawa state, Nigeria. The suggestions and recommendations arising from the study will help solve this problem in future, so that parents themselves will achieve the aim of sending their children to school.

\section{Statement of the Problem}

Education is the right of every child. However, it is a mirage in the lives of some Nigerian children. This is because some of them are forced to be out of school for one reason or the other. The regression in basic education is reflected in the fact that enrolment rate is very low, with high dropout rate. Poverty has been known to force most parents to withdraw their children from school. UNICEF (2017), report indicates that 12.5 million children are out of school for various reasons. The same report indicates that Nigeria is one of the 25 developing countries of the world with low enrolment rate. This is a problem that requires emergency action if the nation is to advance technologically, economically and socially considering the multiple and intergenerational benefits derivable in the education of our children. It is the aim of this study to find out reasons why students dropout in Zumo Development Area, and consequently, based on the findings, proffer solutions to be adopted in order to check the menace of dropout of school children.

\section{Purpose of the Study}

The purpose of the study was to examine factors that lead to students dropping out from secondary schools in Zumo Development Area, and proffer some suggestions regarding the solution of these problems.

\section{Review of Literature}

School dropout in its simplest meaning is the untimely withdrawal from school. These students who withdraw from school prematurely end up not obtaining any certificate of graduation. The issue of school dropout is a global problem confronting the education industry round the world. The issue of school dropout in Nigeria has been with us for a very long time. Cabus and Witte, (2015) noted that dropout is one of the most serious problems that have continued to bedevil our educational system since Nigerian independence. Even before our independence, the problem of dropout had already established its grip on our educational system. This study has come at a time when there is high rate of insecurity in the country as a result of criminal activities. Survey by both the print and electronic media tends to indicate that over $85 \%$ of the criminal activities perpetuated in Nigeria are done by youths who dropped out of school (Carlson, 2014). This development has become a cause of serious concern to all well-meaning Nigerians. This tends to 
suggest that our educational system is in trouble and thus needs a very serious attention in refocusing it and restructuring it for the attainment of national goals.

Awwal (2015) categorized reasons why students drop out of school into four clusters that include; school related, Job related, family related, and community related. Awwal further identified a number of factors under each cluster as influencing student dropping out of school. The factors identified under family cluster include; low family socioeconomic status, low family support for education, low parental education, conflicts between work and school, having to work and school, having to work or support family, substance use and pregnancy among others.

School Influence: School is the second home for children. It is supposed to be an institution that educates personalities, if the students are not taught well in school, it could lead to drop out, hence students should be 'motivated' in and outside the classroom activities. A motivated child will always want to read more by going to library after school; he will not want to be free from his books. Benjamin, Ronald and Catherine, (2015) also proved that years of research have focused on personal characteristics of high school dropout. They stated that lack of diversity in the school curriculum can predispose students into dropping out of school. The influence of school-related factors such as school policies and practices; student teacher relationships; nature of the school curriculum; resources and quality of learning are central to the dropping out of school. Under school related cluster, Benjamin, further observed factors such as; low socioeconomic status of school population, high level of racial or ethnic discrimination of students, school phobia, school violence, conflicts (with teachers, school mates) among others. The job related cluster entails: those students who could not work and school at the same time, those who had to do a job to survive and those who found job while in the community cluster, the following factors were identified: living in a low income neighbourhood, having peers with low educational aspirations and having friends or siblings who are dropouts (Benjamin, Ronald and Catherine, 2015).

Studies in kenya (Şeyma, Zeynep, and Abdurrahman, 2016)) found financial difficulties, lack of interest in studies, parents lukewarm attitude, lack of education facilities in villages, lack of quality education, imposition of parents' choices upon adolescents, lack of privacy, and toilet facilities for students are some of the reasons for dropping out school. Ahmad and Najeemah, (2015) observed that the problem of drop outs is equally acute in Nigeria secondary schools. Many children enter secondary school with the purpose of obtaining school certificate that will enable them go to higher institution or at least earn a living, but owing to lack or poor direction from teacher misguidedness, wrong choice of subject and so on. They failed to obtain these certificates and finally drop out of the school. He further stated that association with drop out from system is the problem of drop out from ones set in the school system in resulting in reputation. Many children repeat classes or fail out of their set in the school because of lack of proper adjustment to the school environment. A break in communication between students and the school, the child not knowing exactly what is required of him or her by the school. It could be as a result of wrong use of poor interpretation of the instrument of measurement used for test or examination upon which promotion is based.

Family Related Factors: Factors associated with failure to complete secondary school education or student dropout include family conditions, family structure, family size, low income, educational status of parents, hard labour family, minority community, mobility, and parents and children's perspective of education. Benjamin, Ronald and Catherine, (2015) stated that family relationships and home climate of the drop out are relatively unhappy. Benjamin 
conducted a large scale study between drop outs and the graduates and their families, the subjects in both groups were white adolescent males who were matched for several factors such as sage, academic ability and family income. According to him, from the analysis of the responses of the drop outs, he was able to judge that the over whelming majority saw their family members as failing to accept each other as individuals, there seemed to be little communication and understanding among the family members, the family lacked solidarity and congeniality and in general it was perceived by the drop outs as unhappy ones. And also talking about the home background factors, Estevao and Alvares, (2014) described dropouts as coming from low-income families whose parents had little or no education, and who were unemployed or had jobs that gave them little or irregular income. The study also identified reasons for dropping out such as poor health due to malnutrition, distance between home and school, lack of interest in the school system. Estevao and Alvares further states that parents of low status are at a disadvantage in trying to control their children, this is a fact because the expectation of the children are not met by their parents, who cannot buy writing materials, books or even school uniform for him or her child, such a child would be exposed to humiliation and would be frustrated, thus this could lead to drop out.

Impact of Indiscipline: Indiscipline in the society has led to many drop outs in schools and thereby increasing the wave of armed robbery and prostitution among young boys and girls in Nigeria. The pathetic situation is that majority of these dropouts are mostly from well to do homes because they lack that aspect of discipline in them. They don't face their studies in which they were sent out for by their parents; instead they join gangs (Foley, Gallipoli and Green, 2014). Many parents are showing immature attitude towards parenthood and finding it extremely difficult to combine the modern way of living to the upbringing of their children. Parents are expected to lay a solid foundation for the personality formation of their children that is, if a child grows up in a home where material wealth is emphasized in place of moral and good name, the child will grow up to be greedy, arrogant, selfish and indiscipline which will soon lead to dropout. Humm, (2018) in his contribution 'attributed indiscipline among students to indiscipline in the society, peer group, school, mass media and individual which contributed to a large degree to student's dropout.

Impact of Poverty: Studies revealed that poverty and social deprivation have a negative impact in school performance of some children. (Johannes, Ayodo and Nelson (2017) revealed that poverty manifest itself in children in the form of malnutrition which can trigger off several diseases, lack of books and educative motivating materials and gadgets at home may also lead to a poor academic performance which consequently may lead to dropping out of school. A child who lacks the necessary materials, writing materials, poorly fed and who gets little or no encouragement from his or her parents are prone to dropping out of the school system. It would be reflected in the child's appearance and dressing because most of them come to school in worn out uniform, bare footed and some without proper uniforms and are therefore exposed to greater risk of having poorer grades than other students and more likely to drop out. A child who lack necessary materials can hardly progress at the same rate with the one who gets all necessary care and attention from his parents, to this end, the unfortunate situation may eventually lead to backwardness in class and in other activities, thus making the child to repeat a class and if there is no improvement, this will lead to dropping out of school. 
Parents Educational Attainment: Humm, (2018), opined that children from low educational or uneducated families are often associated with more dropouts and failures. This proves that the parents' perception of the importance of education depends on their own educational level. The ability of parents to participate in the teaching process is increasing as the general educational level of the adult population rises. According to Stempel, Cox-Martin, Bronsert, Dickinson, ands Allison, (2017), parental education decides the family life style, the income occupation and the social life; they believe that there is a very strong relationship between occupation and education. They further stated that form many studies have shown that even when children of comparable intelligence are compared, social class background make a great deal of difference in the achievement of the children. This is true because of the fact that parents from wealthier families tends to be better educated and can therefore be of greater assistance both materially and intelligently to their children, the reason for this being that educationally qualified parents to a very large extent motivate their children parents to a very large extent motivate their children at home, this they do by providing academic, promoting gadgets, payment for extra lesson, assisting the children in their take home assignments and a host of others.

Poor Academic Achievement: Teaching methods and curriculum are equally significant causes for school children to dropout from schools. Fan and Wolters (2014) examined the dropout phenomenon with respect to irrelevant curriculum related factor. It was found that irrelevant curricula and the lack of educational programs influenced the dropout behaviour in schools. The dropout phenomenon occurred because the curriculum was unable to meet the individual's vocational and intellectual needs. He also found that school distance, inadequate resources and facilities were a major reason for premature school dropout. He concluded that the school should expand and engage in meaningful curriculum to meet the students varied interests, needs, and aptitudes to reduce the dropout rates.

Consequences of Dropout: The attendant problem of dropout cannot be over emphasized, dropping out of school has become societal or better still a worldwide problem. According to Cabus and Witte (2015), dropout among secondary school students can lead to; early marriages; insecurity in the society, armed robbery; unwanted pregnancy; high rate of abortion; human trafficking and drug trafficking and breakdown of rules and regulations and so on. Delinquency and unemployment have led most Nigeria robbers and hired assassins, even majority of the students in school feel that you can only be assured of adequate security. If you join a secret society and carry guns the whole country is no longer safe as parents do not trust their own children, unwanted pregnancies, youthful marriages, trial marriages and divorce are no longer new in our society.

\section{Research Questions}

The study was guided by the following research questions:

i. What are the possible reasons for students' dropout in Zumo secondary schools?

ii. To what extent does the student-teacher relationship influence students' decision to drop out of school?

iii. To what extent does the school curriculum influence students' decision to drop out of school?

iv. To what extent does the family background influence students' decision to drop out of school? 


\section{Research Methodology}

The study employed the descriptive survey design. This method focused on systematic description or exposure of the salient aspects of a situation with a focus on the patterns that emerge. Since the focus was the breadth of the findings the descriptive survey methodology was found suitable for the study. The study was analytic (qualitative) in that the researcher focused on the relationships between variables and further interpreted the relationships. The survey design was preferred because it is the most appropriate design where self-reported beliefs and opinions of participants are sought. The population consisted of all the secondary schools in Zumo Development Area of Song local Government Area. The target population was 50 form three students who had dropped out of school during the past five years. Twenty students (10 male and 10 female) from five randomly selected secondary schools in the cluster were chosen through purposive or judgmental sample of four students per school to participate in the study. The reason for using Form three students was that the students have acquired valuable experiences concerning the actors that predispose students into dropping out at that level. Therefore, they would be in a better position to provide fairly credible and valid data about the phenomenon under study.

Data was collected from students in the selected schools. The four point scale employed in rating the responses of the respondents to the items in the instruments were a modified Likert-type four-point rating scale with the numerical values of 4, 3,2 and 1 assigned to the points was employed in seeking answers to the research questions. The cut-off point for the rating scale was 2.50 , obtained by dividing the sum of the numerical value by the number of scaling items. Splithalf technique was used to test reliability where it required only one testing session. In this approach, an instrument was designed in such a way that there were two parts. Respondents' scores from odd numbers correlated with scores from even numbers. Piloting was done to establish the clarity of meaning and comprehensibility of each item in the research instruments. The content validity of the instrument was determined by experts in curriculum and psychology departments respectively, who establish the appropriateness and suitability of the items in the instrument.

\section{Results and Discussion}

The first research question required participants to indicate the causes of dropping out of school. The participants cited various reasons for school dropout.

Research Question 1: What are the possible reasons for students' dropout in Zumo secondary schools?

Table 1: Causes of students' dropping out of school

\begin{tabular}{|c|c|c|c|c|c|c|}
\hline SN & ITEM & $\mathbf{S A}$ & $\mathbf{A}$ & $\mathbf{D}$ & SD & $\begin{array}{l}\text { TOTAL } \\
\%\end{array}$ \\
\hline 1 & Poverty & $35 \%$ & $45 \%$ & $15 \%$ & $5 \%$ & $100 \%$ \\
\hline 2 & Poor Academic Performance & $20 \%$ & $55 \%$ & $10 \%$ & $15 \%$ & $100 \%$ \\
\hline 3 & Bad School Administration & $30 \%$ & $35 \%$ & $15 \%$ & $20 \%$ & $100 \%$ \\
\hline 4 & Early Forced Marriage & $25 \%$ & $35 \%$ & $15 \%$ & $25 \%$ & $100 \%$ \\
\hline 5 & Child Labour & $5 \%$ & $10 \%$ & $35 \%$ & $50 \%$ & $100 \%$ \\
\hline 6 & Low Parental Education & $15 \%$ & $30 \%$ & $20 \%$ & $35 \%$ & $100 \%$ \\
\hline 7 & School Distance from Home & $25 \%$ & $15 \%$ & $35 \%$ & $25 \%$ & $100 \%$ \\
\hline 8 & Lack of Qualified Teaching Staff & $40 \%$ & $30 \%$ & $25 \%$ & $5 \%$ & $100 \%$ \\
\hline
\end{tabular}


International Journal of Current Aspects, Volume 4, Issue 1, 2020, PP 22-32, ISSN 2616-6976 i]JCAB

\begin{tabular}{lllllll}
\hline SN & ITEM & SA & A & D & SD & $\begin{array}{l}\text { TOTAL } \\
\mathbf{\%}\end{array}$ \\
\hline $\mathbf{9}$ & Lack of Motivation & $30 \%$ & $30 \%$ & $25 \%$ & $15 \%$ & $100 \%$ \\
$\mathbf{1 0}$ & Influence of Peer Group & $25 \%$ & $30 \%$ & $30 \%$ & $15 \%$ & $100 \%$ \\
\hline
\end{tabular}

Table 1 reveals that the possible reasons for students leaving schools before the completion of their studies were poverty $(80 \%)$, poor academic performance, $(75 \%)$ and bad school administration $(75 \%)$ as expressed by the respondents. The findings from this study were consistent with previous findings by Şeyma, et al (2016) who identified economic recession as one of the reasons for dropout. The level of education of most parents in rural areas is very low and hence do not see the need of sending their wards to school. Due to poor primary and junior secondary education backgrounds most students in rural areas are low academic achievers and end up dropping out from school.

Research Question 2: To what extent does the student-teacher relationship influence on students' decision to drop out of school?

Table 2: Student-teacher relationship and its influence on students' decision to drop out of school

\begin{tabular}{lllllll}
\hline SN & ITEM & SA & A & D & SD & $\begin{array}{l}\text { TOTAL } \\
\mathbf{\%}\end{array}$ \\
\hline $\mathbf{1}$ & Poor Teaching Methods & $65 \%$ & $20 \%$ & $10 \%$ & $5 \%$ & $100 \%$ \\
$\mathbf{2}$ & Conflicts with teachers & $55 \%$ & $35 \%$ & $5 \%$ & $5 \%$ & $100 \%$ \\
$\mathbf{3}$ & Teachers' uncaring behavior & $70 \%$ & $15 \%$ & $10 \%$ & $5 \%$ & $100 \%$ \\
\hline $\mathbf{4}$ & Discrimination by teachers & $60 \%$ & $20 \%$ & $10 \%$ & $10 \%$ & $100 \%$ \\
$\mathbf{5}$ & punishment by teachers & $65 \%$ & $25 \%$ & $5 \%$ & $5 \%$ & $100 \%$ \\
$\mathbf{6}$ & Teachers negative comments & $75 \%$ & $15 \%$ & $5 \%$ & $5 \%$ & $100 \%$ \\
$\mathbf{7}$ & Teachers Lackadaisical attitudes & $65 \%$ & $20 \%$ & $5 \%$ & $10 \%$ & $100 \%$ \\
$\mathbf{8}$ & Teachers domination of class session & $40 \%$ & $30 \%$ & $25 \%$ & $5 \%$ & $100 \%$ \\
\hline
\end{tabular}

Table 2 shows that majority of students agreed that having conflicts with teachers $(90 \%)$, cruelty by teachers $(90 \%)$, negative comments passed by teachers $(90 \%)$, teachers' uncaring behavior (85\%), and poor teaching methods (85\%) predispose students into dropping out of school, while 15 percent disagreed with this view. On the other hand, $10 \%$ of the respondents thought otherwise. Discrimination was cited by 80 percent of the respondents as central to the dropping out while 20\% refuted this view. The data clearly indicates that the majority (90\%) cited teachers' lack of care and concern about whether they will pass or not, the negative comments they pass teachers' cruelty as well as conflicts with teachers as closely related to dropping out.

The above findings are consistent with findings by Fan, et al (2014) who found out that neglect by teachers, poor teaching, discrimination, cruelty or punishment meted out by teachers, absence 
as being among the teacher centric reasons for dropping out of school in rural settings in India. A positive relationship between students and teachers reduces the probability of dropping out by nearly half. Such a relationship is important particularly to students with disadvantaged backgrounds and those experiencing academic difficulties that are at risk of dropping out.

Research Question 3: To what extent does the school curriculum influence students' decision to drop out of school?

Table 3: The School Curriculum and its Influence on Students' Decision to Drop Out of School

\begin{tabular}{lllllll}
\hline SN & STATEMENT & SA & A & D & SD & $\begin{array}{c}\text { TOTA } \\
\text { LO }\end{array}$ \\
\hline $\mathbf{1}$ & Lack of diversity in the curriculum & $65 \%$ & $25 \%$ & $5 \%$ & $5 \%$ & $100 \%$ \\
\hline $\mathbf{2}$ & Curriculum irrelevant to the world of work & $75 \%$ & $15 \%$ & $5 \%$ & $5 \%$ & $100 \%$ \\
$\mathbf{3}$ & Curriculum not catering for learners' interest & $80 \%$ & $15 \%$ & $5 \%$ & $0 \%$ & $100 \%$ \\
$\mathbf{4}$ & Lack of pay off and upward mobility & $70 \%$ & $20 \%$ & $5 \%$ & $5 \%$ & $100 \%$ \\
$\mathbf{5}$ & Poor job opportunities after school & $65 \%$ & $25 \%$ & $5 \%$ & $5 \%$ & $100 \%$ \\
\hline
\end{tabular}

Table 3 revealed that curriculum not catering for learners' interest (95\%), lack of diversity in the curriculum (90\%) with limited choices and options for students' interest predisposes students to dropping out. On the other hand, $90 \%$ do think that a curriculum that is irrelevant to the world of work is a factor in the dropping out problem; $95 \%$ and $90 \%$ respectively believe that lack of pay off in terms of income, upward mobility and job opportunities cause students to lose confidence in education hence dropout.

The above findings are consistent with findings by Muhammed, Sivapalan, and Junaenah (2017) who observed that curriculum related factors contribute to students' high dropout rate. Students feel bored and not satisfied with the prescribed curriculum which does not fulfil the needs and expectations of the community. Therefore, students do not take interest in their education and they leave the school. Muhammed, Sivapalan, and Junaenah further maintain that to help students stay in school the following should be observed: (i) improve teaching and curricula to make school more relevant and engaging to enhance the connection between school and work; (ii) improve instruction and access to support for struggling students; (iii) ensure strong adultstudent relationships within the school; (iv) build a student relationships within the school; and (v) improve the communication between parents and school. The education system should therefore inculcate proper work ethics and it is the duty of schools to develop job-related competencies in students so that they are motivated to pursue a qualitative and functional education. 
Research Question 4: To what extent does the school environment influence students' decision to drop out of school?

Table 4: Influence of school environment on students' decision to drop out of school

\begin{tabular}{lllllll}
\hline SN & ITEM & SA & A & D & SD & TOTAL \\
\hline $\mathbf{1}$ & Lack of adequate Facilities in Schools & $15 \%$ & $80 \%$ & $5 \%$ & O\% & $100 \%$ \\
$\mathbf{2}$ & Dilapidated School Structure & $20 \%$ & $70 \%$ & $5 \%$ & $5 \%$ & $100 \%$ \\
$\mathbf{3}$ & Lack of adequate School Resources & $15 \%$ & $75 \%$ & $5 \%$ & $5 \%$ & $100 \%$ \\
$\mathbf{4}$ & Geographical Factors & $5 \%$ & $80 \%$ & $10 \%$ & $5 \%$ & $100 \%$ \\
$\mathbf{5}$ & Lack of Sporting Activities & $20 \%$ & $60 \%$ & $10 \%$ & $10 \%$ & $100 \%$ \\
\hline
\end{tabular}

Table 4 shows that with regard to the school physical environment, the majority of students agree that lack of facilities (95\%), lack of resources (90\%), and poor condition of infrastructure (90\%), geographical factors (85\%) and administrative factors $(80 \%)$ are among the main causes of school dropout. The findings have also shown that geographical factors prove to be a barrier for some children continuing in school. Long distances of schools from homes and poor transportation facilities are also main causes of dropout. Schools in rural areas of the country, especially remote rural areas, lack of basic facilities of life such as good roads, education and health facilities which causes the students dropout and retention rate. The study also revealed that poor condition of school buildings and inadequate or lack of resources such as textbooks, desks and blackboards influence dropout of students from school (Mohamed, Sivapalan and Junaenah 2017).

\section{Conclusion}

The dropout phenomenon has been observed to be very complex with multiple interwoven factors responsible for leading to this complex situation. This study has made modest attempt to explore this complex phenomenon with reference to school based factors as contributing to this phenomenon. It was found that families with low socio-economic background experience high rate of school dropout. The study has also revealed that certain school conditions can lead to school dropout. Thus, schools appear to influence dropout behaviour through their organization, structure and the school climate. Other related factors include school distance, inadequate resources and lack of school facilities are among the main causes of school dropout among rural secondary school students in Zumo. Similarly, poor teacher-student relationship, teachers' uncaring behaviour, cruelty, frequent use of corporal punishment, negative comments on students and poor use of teaching methods have negatively contributed to school dropout. Students may also be dropped out of school because of curriculum related factors. It was noted that lack of education programs to meet the individual's vocational and intellectual needs of the students ultimately leads to dropout while an irrelevant, complex, rigid and congested curriculum puts learners off and predisposes them to dropping out. 


\section{Recommendations}

Based on findings and conclusions, the following recommendations were made:

i. Parents are advised to ensure a favourable home environment for their children and pay proper attention to the educational and financial specific needs of their children.

ii. Awareness campaign regarding importance of education in society should be ensured through electronic as well as print media to reduce the dropout rate.

iii. Curriculum should be reviewed and redesigned in the light of emerging needs of students and society.

iv. School principals and teachers are advised to ensure conducive learning environment inside the school for their students.

v. Competent and qualified teachers be appointed purely on merit basis through transparent competitive examination.

\section{References}

Ahmad K, Najeemah, M. Y, \&Jamalsafri, S. (2017). Relationship between parental economic factors, and students' dropouts from government secondary schools of Zamfara, Nigeria. Asia Pacific Journal of Educators and Education, 32, $29-43$.

Ahmad, K, \& Najeemah, M. Y. (2015), Students' perspective on female dropouts in Nigeria Research in Higher Education Journal Volume 2, (15) Pages 45-52.

Awwalu, M. I. \& Najeemah, M. Y, (2014). Does home and school factors predicts students dropout in Sokoto Nigeria? International Journal of Education and Research, 2 (6), pages 60-65.

Benjamin, K. Ronald, T. \& Catherine, S. (2015). School based factors as determinants of secondary school students drop out in Bomet county, Kenya.International Journal of Education and Research, 3 (3),pages 30-34.

Cabus, S. J. \& Witte, K. (2015). The effectiveness of active school attendance interventions to tackle dropout in secondary schools: A Dutch Pilot Case. Empirical Economics, 49 (1), 65-80.

Carlson, C. L. (2014). Dropout factories and the vaccination approach: The Impact of the Dropout Rate on the Economy and the Need for Effective Literacy Instruction. SRATE Journal, 23 (2), 1-7.

Estevao, P. \& Alvares, M. (2014). What do we mean by school dropout? Early School Leaving and the Shifting of Paradigms in School Dropout Measurement. Portuguese Journal of Social Science, 13 (1), 21-32.

Fan, W. \& Wolters, C. A. (2014). School motivation and high school dropout: The Mediating Role of Educational Expectation. British Journal of Educational Psychology, 84, 22-39.

Foley, K., Gallipoli, G., \& Green, D. A. (2014). Ability, parental valuation of education, and the high school dropout decision. The Journal of Human Resources 49 (4), 906-942.

Humm B. A, Castillo, J. M, \& Batsche, G. M. (2017). Reasons for chronic absenteeism and drop out among secondary students: Survey Summary Report. Tampa, FL: Florida's Problem Solving \& Response to Intervention Project.

Johannes K . K, Ayodo, T.M.O. \& Nelson, N. N. (2017). Causes of high dropout rates of students in secondary schools in Kipkelion Sub-County, Kericho County, Kenya. Kabarak Journal of Research \& Innovation Volume 5 Number 1 (2017) ISSN 2305-784X (print) ISSN 2410-8383 (online) http://eserver.kabarak.ac.ke/ojs/ 
Mohammed, I . R, Sivapalan, S, \& Junaenah S. (2017). Social environmental determinants of student dropout in the plantation settlement. Malaysian Journal of Society and Space $\mathbf{1 3}$ issue 2 (54-64)

Şeyma, Ş. Zeynep, A \& Abdurrahman K. (2016). Causes of student absenteeism and school dropouts. International Journal of InstructionVol.9, No.1 e-ISSN: 1308-1470

Stempel, H., Cox-Martin, M., Bronsert, M., Dickinson, L. M., \& Allison, M. A. (2017). Chronic school absenteeism and the role of adverse childhood experiences. Academic Pediatrics, 17, $837-843$.

United Nations Children's Fund (UNICEF). (2017). Multiple indicator cluster survey 2016-17, Survey Findings Report. Abuja, Nigeria.

This is an open-access article published and distributed under the terms and conditions of

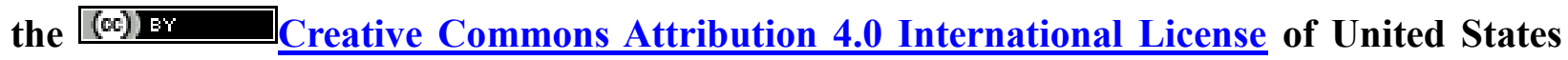
unless otherwise stated. Access, citation and distribution of this article is allowed with full recognition of the authors and the source.

Authors seeking to publish with an International Peer Reviewed Journal should consider https://www.ijcab.org/ by writing to the Editor at editor@ijcab.org. The articles must be quality and meet originality test. 